\title{
PENERAPAN LEAN MANUFACTURING DI PT. PIPA MAS PUTIH, BATAM
}

\author{
Haris Adi Swantoro', Akhmad Nidhomuz Zaman², Merike Widi Safitri ${ }^{3}$, Rahmayanti Wulandari ${ }^{4}$ \\ Teknik Industri, Universitas Pembangunan Nasional Veteran Jakarta ${ }^{12} 34$ \\ Email²: akhmadzaman19@gmail.com
}

\begin{abstract}
Abstrak
Persaingan di dunia industri saat ini semakin tinggi, perusahaan dituntut untuk dapat terus meningkatkan performanya, salah satunya dengan usaha meningkatkan produktivitas. PT. Pipa Mas Putih plant Batam merupakan perusahaan produksi screen dan OCTG pipes. Perusahaan ini menyokong kebutuhan pipa untuk perusahaan oil \& gas. Di dalam proses produksi Tubing $31 \frac{1}{2}$ "93.30 PFF, J-55, EU, 8-RD, R-2 sering mengalami kemunduran lead time akibat kurang optimalnya produktivitas produksi dan menyebabkan terjadinya idle time yang teridentifikasi di lapangan. Penelitian dilakukan untuk mengetahui nilai selisih waktu total aktivitas aktual dan usulan setelah minimasi di dalam proses produksi produk OCTG dan mengidentifikasi pemborosan yang terjadi di PT. Pipa Mas Putih plant Batam. Hasil yang didapat: Banyaknya aktivitas produksi sebesar 38 aktvitas. Besar total waktu aktual sebesar 143,11 menit dan total waktu usulan sebesar 124,44 menit. Terjadi penurunan total waktu sebesar 18,67 menit. Pemborosan yang teridentifikasi mempunyai ranking tertinggi yaitu waiting, unnecessary motion, dan inappropriate processing. Teknik Lean Manufacturing membantu perusahaan untuk menjadi kompetitif, dalam hal pengurangan waste dalam operasi dengan memaksimalkan aktivitas yang bernilai tambah.
\end{abstract}

Kata kunci: idle time, lean, minimasi, tubing, waiting

\begin{abstract}
Competition in the industrial world is currently increasingly high, companies are required to be able to continue to improve their performance, one of which is by efforts to increase productivity. PT. Pipa Mas Putih plant Batam is a screen production company and OCTG pipes. This company supports the needs of the pipeline for oil \& gas companies. In the Tubing 31/2 "93.30 PFF, J-55, EU, 8-RD, R-2 Tubing production process often leads to a lead time setback due to less than optimal production productivity and causes the idle time to be identified in the field. The study was conducted to determine the value of the total time differences between the actual activity and the proposal after minimization in the production process of OCTG pipes products and identify the waste that occurred at PT. Pipa Mas Putih plant Batam. The results obtained: The number of production activities of 38 activities. The actual total time is 143.11 minutes and the total proposed time is 124.44 minutes. A total time reduction of 18.67 minutes occurred. The waste identified as having the highest rank is waiting, unnecessary motion, and inappropriate processing. Lean Manufacturing techniques help companies to be competitive, in terms of reducing waste in operations by maximizing value-added activities.
\end{abstract}

Keywords: idle time, lean, minimization, tubing, waiting

\section{PENDAHULUAN}

Persaingan di dunia industri saat ini semakin tinggi, perusahaan dituntut untuk dapat terus meningkatkan performanya, salah satunya dengan usaha meningkatkan produktivitas. Proses produksi diupayakan untuk memberikan kontribusi penuh terhadap kegiatan yang berkaitan dengan nilai tambah dan diharuskan untuk menghindari dan meminimalkan idle/delays, loading-unloading, set up, material handling dll (Wignjosoebroto, 1995). Berdasarkan pada kondisi perusahaan yaitu manufaktur make to order. Make to order atau manufaktur dengan high mix - low volume yang berarti bahwa terjadinya perubahan lini produksi yang berupa lot dan tidak ada peramalan permintaan pesanan untuk 
menjadwalkan dalam jalur produksi, bekerja hanya dengan skema kerja dan menjadikan waktu sebagai asset terbesar bagi perusahaan (Lane, 2000 dalam Nuruddin et al., 2013). Adanya idle di dalam proses produksi mengakibatkan kegiatan menjadi kurang efektif dan efisien, sehingga perlu adanya pengeliminasian terhadap pemborosan (waste) dengan menggunakan metode lean manufacturing.

PT. Pipa Mas Putih merupakan perusahaan produksi screen dan OCTG pipes. Perusahaan ini menyokong kebutuhan pipa untuk perusahaan oil \& gas. Pengendalian kualitas pada proses produksi di PT. Pipa Mas Putih di Batam dengan adanya in-line inspection dan final inspection. Standar yang digunakan API 5CT, API Specification Q1, ISO 9001, OHSAS 18001, ISO 14001, API 7-1.

Di dalam proses produksi Tubing $31 \frac{1}{2}$ " 93.30 PFF, J-55, EU, 8-RD, R-2 sering mengalami kemunduran lead time akibat kurang optimalnya produktivitas produksi dan menyebabkan terjadinya idle time yang teridentifikasi di lapangan. Penelitian dilakukan untuk mengetahui nilai selisih waktu total aktivitas aktual dan usulan setelah minimasi di dalam proses produksi produk OCTG dan mengidentifikasi pemborosan yang terjadi di PT. Pipa Mas Putih plant Batam. Dengan menggunakan metode lean manufacturing digunakan untuk meningkatkan nilai tambah (value added) dengan pemanfaatan segala sumber daya. Teknik Lean Manufacturing membantu perusahaan untuk menjadi kompetitif, dalam hal pengurangan waste (pemborosan) dalam operasi dengan memaksimalkan aktivitas yang bernilai tambah (value added) (Forrester 1995 dalam Kurniawan, 2012) serta Perusahaan yang membudayakan lean akan bisa mereduksi aktivitas yang tidak bernilai dan pelanggan pun tidak akan merasa rugi (Damayanti 2017 dalam Zaman et al, 2017).

\section{TINJAUAN PUSTAKA \\ Lean Manufacturing}

Lean berarti rangkaian aktivitas atau solusi untuk mengeliminasi waste, mereduksi operasi nonvalue added (NVA) dan meningkatkan operasi value added (VA) (Wee, 2009).

Jenis-jenis aktivitas berdasarkan value konsumen menurut Womack dan Jones (1996):

1. Value Added Activities, aktivitas untuk menghasilkan produk atau jasa yang memberikan nilai tambah dimata konsumen.

2. Necessary but Non-Value Added Activities, aktivitas yang tidak memberikan nilai tambah di mata konsumen pada material atau produk tetapi perlu dilakukan.

3. Non Value Added Activities, aktivitas yang tidak memberikan nilai tambah di mata konsumen pada suatu material atau produk.

\section{Waste}

Terdapat 7 pemborosan yang harus dieliminas yaitu overproduction, waiting, transportation, overprocessing, unnecessary inventory, unnecessary motion, dan defect). Waste harus dihilangkan guna meningkatkan nilai produk dan selanjutnya meningkatkan customer value (Åhlström, 1998)

\section{Value Stream Mapping}

Menurut Womack dan Jones, Value stream mapping (VSM) digunakan sebagai alat untuk memudahkan proses implementasi lean dengan cara membantu mengidentifikasi tahapan-tahapan valueadded di suatu aliran proses (value stream), dan mengeliminasi tahapan-tahapan non-value added atau waste.

\section{VALSAT Tools}

VALSAT berdasarkan (Daonil, 2012) memberikan pengukuran subyektif dan obyektif yang dapat diterapkan dalam berbagai posisi value stream.

\begin{tabular}{|l|c|c|c|c|c|c|c|}
\multicolumn{7}{c}{ Tabel 1. Faktor Pengali VALSAT } \\
\hline \multirow{2}{*}{\begin{tabular}{|c|c|c|c|c|c|c|} 
Waste/Structure \\
\end{tabular}} & $\begin{array}{c}\text { Process } \\
\text { Activity } \\
\text { Mapping }\end{array}$ & $\begin{array}{c}\text { Supply } \\
\text { Chain } \\
\text { Response } \\
\text { Matrix }\end{array}$ & $\begin{array}{c}\text { Production } \\
\text { Variety } \\
\text { Funnel }\end{array}$ & $\begin{array}{c}\text { Quality } \\
\text { Filter } \\
\text { Mapping }\end{array}$ & $\begin{array}{c}\text { Demand } \\
\text { Amplification } \\
\text { Mapping }\end{array}$ & $\begin{array}{c}\text { Decision } \\
\text { Point } \\
\text { Analysis }\end{array}$ & $\begin{array}{c}\text { Physical } \\
\text { Structure }\end{array}$ \\
\hline Overproduction & $L$ & $M$ & - & $L$ & $M$ & $M$ & - \\
\hline $\begin{array}{l}\text { Defects } \\
\text { Unnecessary } \\
\text { Inventory }\end{array}$ & $M$ & - & - & - & - & - & - \\
\hline $\begin{array}{l}\text { Inappropriate } \\
\text { Processing }\end{array}$ & $H$ & - & $M$ & $L$ & - & $L$ & - \\
\hline $\begin{array}{l}\text { Excessive } \\
\text { Transportation }\end{array}$ & $H$ & - & - & - & - & - & $L$ \\
\hline Waiting & $H$ & $H$ & $L$ & - & $M$ & $M$ & - \\
\hline $\begin{array}{l}\text { Unnecessary } \\
\text { Motion }\end{array}$ & $H$ & $L$ & - & $H$ & - & - & - \\
\hline
\end{tabular}

Keterangan (faktor pengali):

$\mathrm{H}$ (high correlation and usefulness $)=9$

$\mathrm{M}$ (medium correlation and usefulness $)=3$

$\mathrm{L}($ low correlation and usefulness $)=1$

\section{Fishbone Diagram}

Fishbone Diagrams (Diagram Tulang Ikan) merupakan konsep analisis sebab akibat untuk mendeskripsikan suatu permasalahan dan penyebabnya dalam sebuah kerangka tulang ikan.

\section{METODOLOGI PENELITIAN}

Pada penelitian ini, tempat pengambilan data di lakukan di PT Pipa Mas Putih. Dalam penelitian ini metode penelitian dilakukan dengan tahapantahapan sebagai berikut:

1. Tahapan identifikasi waste dengan memberikan kuisioner (10 responden) kepada beberapa yang berhubungan dengan proses produksi.

2. Melakukan pembobotan waste dengan tujuan untuk mengidentifikasi waste yang terjadi pada bagian poses produksi.

3. Melakukan analisa dengan memilih tool pada VALSAT untuk membantu mengidentifikasi waste pada individual value stream. 
4. Melakukan analisa faktor penyebab untuk mengetahui faktor penyebab waste yang terjadi pada sistem dengan menggunakan fishbone.

5. Menggambarkan usulan state map berdasarkan rencana solusi prioritas yang telah ditentukan, untuk memahami keadaan dari rencana sistem yang akan datang.

\section{ANALISIS DAN PEMBAHASAN DATA}

Process Activity Mapping menunjukkan aktivitas-aktivitas yang terjadi pada setiap proses beserta waktu yang diperlukan, jarak yang ditempuh setiap aktivitas, dan jumlah operator yang dibutuhkan pada setiap proses. Aktivitas dibagi menjadi lima jenis yaitu operasi, transportasi, inspeksi, delay dan storage (penyimpanan). Aktivitas tersebut kemudian dikategorikan menjadi 3 tipe aktivitas yaitu Value Added (VA), Non Value Added (NVA), dan Necessary but Non Value Added (NNVA).

Berdasarkan perhitungan, total aktivitas yang dibutuhkan untuk memproduksi pipa Tubing 3 1⁄2 93.30 PPF, J-55, EU, 8-RD, R-2 di PT. Pipa Mas Putih sebanyak 38 aktivitas untuk satu kali proses produksi dengan total waktu 143.15 menit per pipa dengan 17 manpower dan total jarak 650 meter. Berikut ini presentase jumlah aktivitas dari PAM Aktual.

Tabel 2. Presentase Jumlah Aktivitas

\begin{tabular}{|c|l|c|c|}
\hline No. & \multicolumn{1}{|c|}{ Aktivitas } & Jumlah & Presentase \\
\hline 1 & Operasi & 13 & $34.21 \%$ \\
\hline 2 & Transportation & 8 & $21.05 \%$ \\
\hline 3 & Inspection & 13 & $34.21 \%$ \\
\hline 4 & Storage & 1 & $2.63 \%$ \\
\hline 5 & Delay & 3 & $7.89 \%$ \\
\hline \multicolumn{2}{|c|}{ TOTAL } & 38 & $100,00 \%$ \\
\hline
\end{tabular}

Sumber: Pengolahan Data, 2019

\section{Presentase Jumlah Aktivitas}

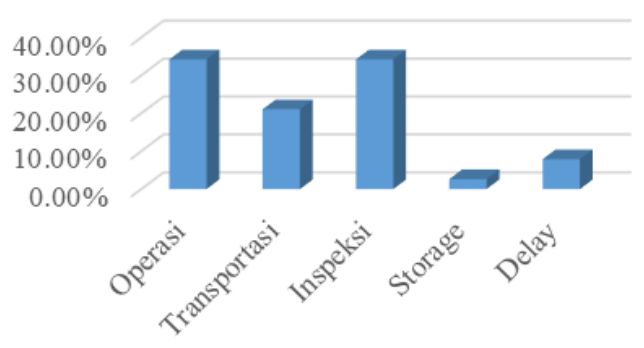

Gambar 1. Grafik Presentase Jumlah Aktivitas

Berikut ini hasil perhitungan presentase waktu total aktivitas berdasarkan kategori aktivitas.
Tabel 3. Presentase Kategori Aktivitas

\begin{tabular}{|c|c|c|c|}
\hline No. & Aktivitas & Jumlah & Presentase \\
\hline 1 & VA & 68,17 & $47,64 \%$ \\
\hline 2 & NNVA & 70,94 & $49,57 \%$ \\
\hline 3 & NVA & 4 & $2,80 \%$ \\
\hline \multicolumn{2}{|c|}{ Total } & 143,11 & $100 \%$ \\
\hline
\end{tabular}

Sumber: Pengolahan Data, 2019

\section{Presentase Kategori Aktivitas}

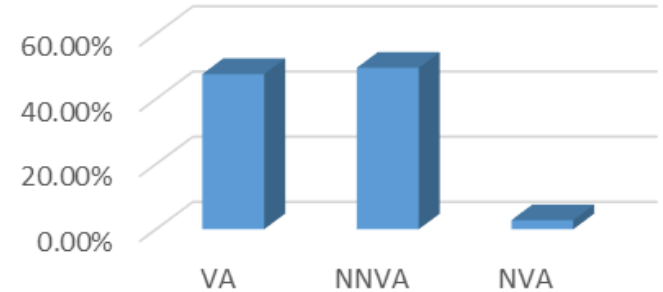

Gambar 2. Grafik Presentase Kategori Aktivitas

Dari PAM Aktual yang telah dibuat, kemudian digambarkan kedalam Value Stream Mapping (VSM) Aktual dengan hasil sebagai berikut.

$$
\text { Value Stream Mapping Aktual }
$$

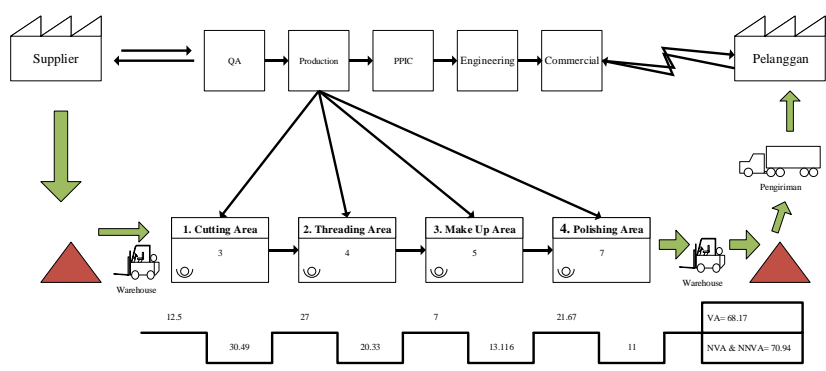

Gambar 3. Value Stream Mapping Aktual

Setelah diketahui VSM Aktual, kemudian dapat diidentifikasi pemborosan (waste) yang terjadi dengan total 10 responden diperoleh hasil rekapitulasi kuesioner 7 pemborosan sebagai berikut.

Tabel 4. Rekapitulasi Kuesioner 7 Pemborosan

\begin{tabular}{|l|l|c|c|c|}
\hline No & \multicolumn{1}{|c|}{ Waste } & Total & $\begin{array}{c}\text { Rata- } \\
\text { rata }\end{array}$ & Rank \\
\hline 1. & Overproduction & 3 & 0.3 & 7 \\
\hline 2. & Defects & 10 & 1 & 6 \\
\hline 3. & $\begin{array}{l}\text { Unnecessary } \\
\text { Inventory }\end{array}$ & 11 & 1.1 & 5 \\
\hline 4. & $\begin{array}{l}\text { Inappropriate } \\
\text { Processing }\end{array}$ & 16 & 1.6 & 3 \\
\hline 5. & $\begin{array}{l}\text { Excessive } \\
\text { Transportation }\end{array}$ & 12 & 1.2 & 4 \\
\hline 6. & Waiting & 25 & 2.5 & 1 \\
\hline 7. & $\begin{array}{l}\text { Unnecessary } \\
\text { Motion }\end{array}$ & 19 & 1.9 & 2 \\
\hline
\end{tabular}

Sumber: Pengolahan Data, 2019 
Berdasarkan hasil identifikasi waste kemudian diketahui bahwa waiting, unnecessary motion, dan inappropriate processing menduduki rank paling atas, sehingga dibuatkan fishbone penyebab terjadinya pemborosa tersebut sebaga berikut.
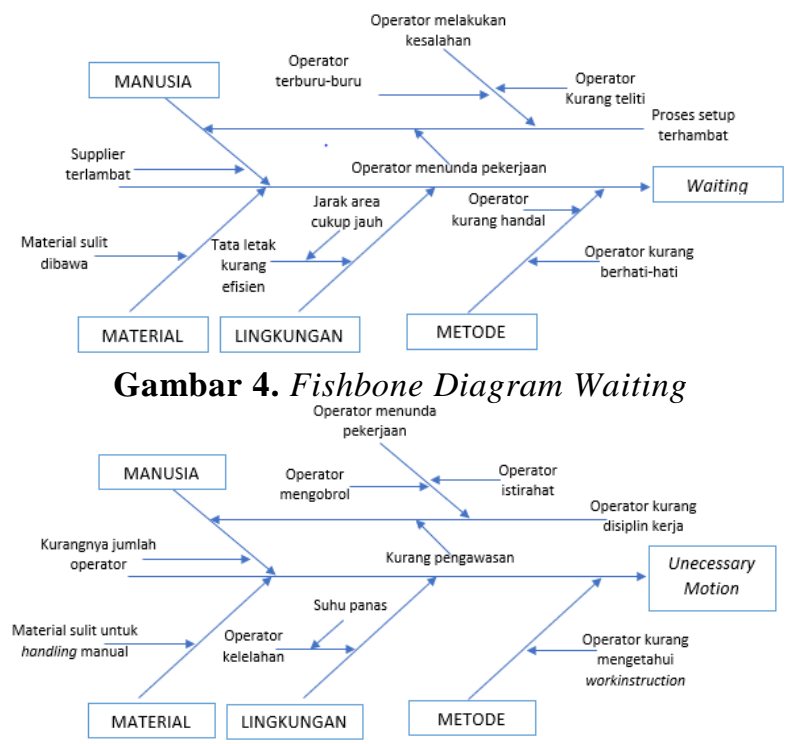

Gambar 5. Fishbone Diagram Unnecessary Motion

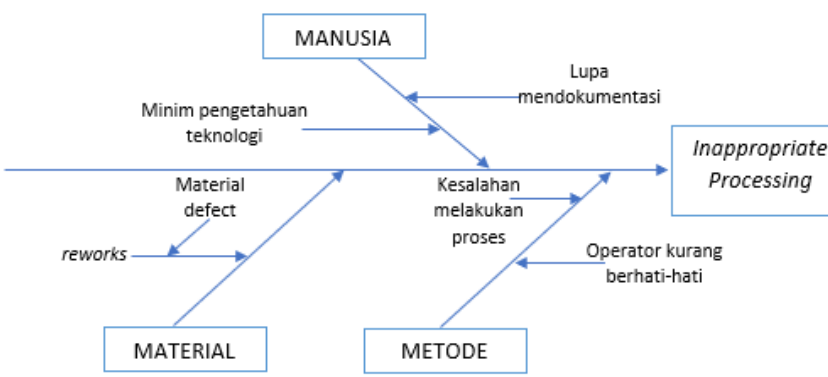

Gambar 6. Fishbone Diagram Inappropriate Processing

Dari tabel di atas, kemudian dilakukan perhitungan Value Stream Analysis Tools (VALSAT) dengan mengalikan faktor pengali VALSAT dan diperoleh hasil nilai tools paling tinggi yaitu Process Activity Mapping (PAM) sebesar 69,4 untuk digunakan sebagai usulan. Berikut ini perhitungan presentase waktu total aktivitas berdasarkan kategori aktivitas sebagai hasil PAM Usulan dari hasil VALSAT.

Tabel 5. Presentase Kategori Aktivitas

\begin{tabular}{|c|c|c|c|}
\hline No. & Aktivitas & Jumlah & Presentase \\
\hline 1 & VA & 68,17 & $47,64 \%$ \\
\hline 2 & NNVA & 58,27 & $49,57 \%$ \\
\hline 3 & NVA & 3 & $2,80 \%$ \\
\hline \multicolumn{2}{|c|}{ Total } & 124,44 & $100 \%$ \\
\hline
\end{tabular}

Sumber: Pengolahan Data, 2019

\section{Presentase Kategori AKtivitas}

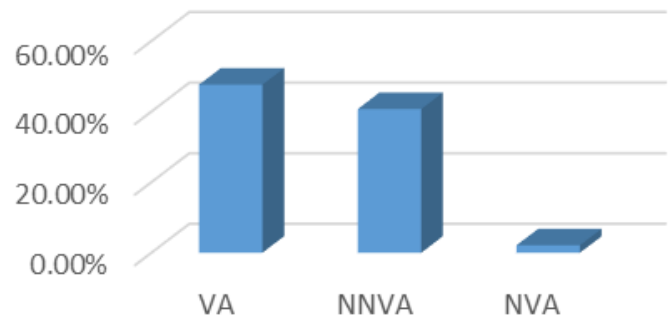

Gambar 7. Grafik Presentase Kategori Aktivitas

Dari PAM Usulan yang telah dibuat, kemudian digambarkan kedalam Value Stream Mapping (VSM) Aktual dengan hasil sebagai berikut beserta perbandingan total waktu aktual dan usulan.

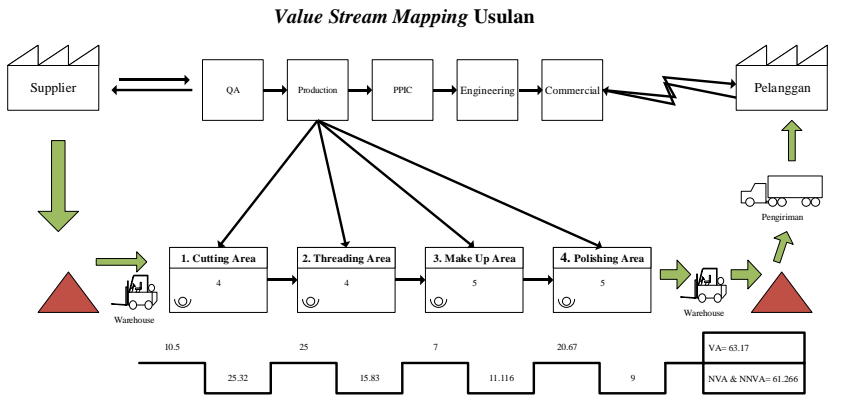

Gambar 8. Value Stream Mapping Usulan Tabel 6. Perbandingan Total Waktu Aktual dan Usulan

\begin{tabular}{|c|c|c|c|}
\hline No. & Aktivitas & Aktual & Usulan \\
\hline 1 & VA & 68,17 & 68,17 \\
\hline 2 & NNVA & 70,94 & 58,27 \\
\hline 3 & NVA & 4 & 3 \\
\hline \multicolumn{2}{|c|}{ Total } & 143,11 & 124,44 \\
\hline
\end{tabular}

Dari tabel di atas, diketahui bahwa telah diperoleh nilai untuk total waktu aktual sebesar 143,11 dan total waktu usulan sebesar 124,44, sehingga penurunan waktu total yang diperlukan untuk memproduksi pipa Tubing $31 \frac{1}{2} 93.30 \mathrm{PPF}$, J-55, EU, 8-RD, R-2 di PT. Pipa Mas Putih sebesar 18,67 menit.

\section{SIMPULAN}

Dari pengukuran dan perhitungan produksi pipa Tubing $31 \frac{1}{2} 93.30 \mathrm{PPF}, \mathrm{J}-55$, EU, 8-RD, R-2 di PT. Pipa Mas Putih dapat disimpulkan bahwa

1. Benyaknya aktivitas untuk melakukan produksi sebesar 38 aktvitas.

2. Besar total waktu aktual sebesar 143,11 menit dan total waktu usulan sebesar 124,44 menit. Terjadi penurunan total waktu sebesar 18,67 menit.

3. Pemborosa yang teridentifikasi mempunyai ranking tertinggi yaitu waiting, unnecessary motion, dan inappropriate processing. 


\section{DAFTAR PUSTAKA}

Daonil., "Implementasi Lean Manufacturing untuk Eliminasi Waste pada Lini Produksi Machining Cast Wheel dengan Menggunakan Metode WAM dan VALSAT'. Universitas Indonesia (UI) Depok. 2012.

Karlsson, C., \& Åhlström, P. Change Processes Towards Lean Production: The Role of the Remuneration System. International. Journal of Operations and Production Management, 15(11), 80-99. 1995.

Kurniawan Taufik., "Perancangan Lean Manufacturing Dengan Metode VALSAT Pada Line Produksi Drum Brake Type Imv (Studi Kasus: PT. Akebono Brake Astra Indonesia)". Universitas Indonesia (UI) Depok, 2012.

Nuruddin, Abdul Wahid., Surachman., Setyanto, Nasir Widha., Soenoko, Rudy. Implementasi Konsep Lean Manufacturing Untuk Meminimalkan Waktu Keterlambatan Penyelesaian Produk "A" Sebagai Value Pelanggan (Stusi Kasus Pt. Tsw (Tuban Steel Work), Universitas Brawijaya Malang, 2013.

Wee, H.; Wu, S."Lean supply chain and its effect on product cost and quality: a case study on Ford Motor Company". Supply Chain Management. An International Journal, Vol. 14, pp.: 335 - 341. 2009.

Wignjosoebroto, Sritomo., "Ergonomi, Studi Gerak dan Waktu. Teknik Analisis Untuk Peningkatan Kerja, Edisi Pertama”. PT. Guna Widya Jakarta, 1995.

Zaman, A.N. Damayanti., T. Rizal, Reda. Analisa pemborosan proses produksi dengan pendekatan lean manufacturing (studi kasus : PT. F). SNIS Seminar Nasional Industrial Services Universitas Sultan Ageng Tirtayasa. Journal Industrial Services Vol. 3 No. 1 Oktober, 2017. 